\title{
Erratum to: Reconstruction of Solar Extreme Ultraviolet Flux 1740 - 2015
}

\section{Leif Svalgaard ${ }^{1}$}

Published online: 5 January 2017

(C) Springer Science+Business Media Dordrecht 2017

\section{Erratum to: Solar Phys (2016) 291:2981 - 3010 DOI 10.1007/s11207-016-0921-2}

Due to an unfortunate turn of events, incorrect versions of Figures 3 and 15 were published. Please find in this erratum the correct versions of Figures 3 and 15, which should be regarded as the final versions by the reader.

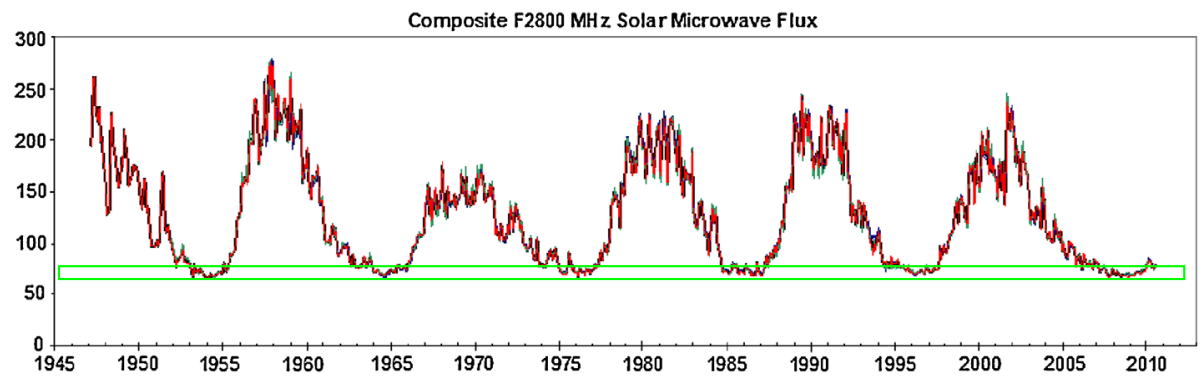

Figure 3 Composite $2800 \mathrm{MHz}$ solar microwave flux (thin-black curve) built from Canadian $2800 \mathrm{MHz}$ flux (red curve), scaled Japanese $3750 \mathrm{MHz}$ flux (green curve), and scaled Japanese $2000 \mathrm{MHz}$ flux (blue curve), Svalgaard (2010). The match is so good that it is difficult to see the individual curves as they fall on top of each other. Note that the values at each sunspot minimum are very similar, without any long-term trend or inter-cycle variation. The green box shows that the flux is very nearly constant at all solar minima.

Sunspot Number Recalibration

Guest Editors: F. Clette, E.W. Cliver, L. Lefèvre, J.M. Vaquero, and L. Svalgaard

The online version of the original article can be found under doi:10.1007/s11207-016-0921-2.

L. Svalgaard

leif@leif.org

1 W.W. Hansen Experimental Physics Laboratory, Stanford University, Cypress Hall C3, Stanford, CA 94305, USA 

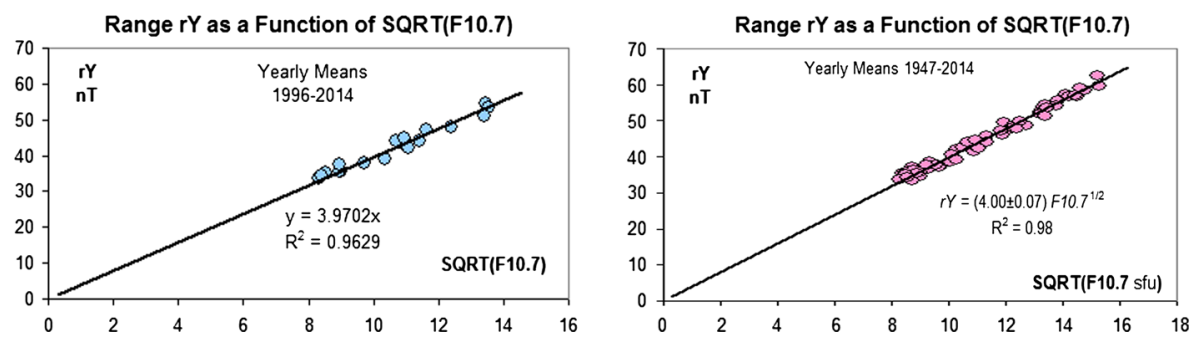

Figure 15 (Left) Yearly average ranges $[r Y]$ plotted against the square root of the $F_{10.7}$ flux for the years 1996-2014 (c.f. Section 4). The offset is negligible so there is simple proportionality as expected. (Right) Extending the regression back to the beginning of the $F_{10.7}$ series in 1947. 